\title{
Restorasi Kepemimpinan Nasional Berlandaskan Nilai Luhur Budaya Bangsa: Studi Kasus Kepemimpinan Ki Hajar Dewantara
}

\author{
Shoffan Mujahid, Mochamad Rifqi Hananto, Nugroho Hasan, Rifqi Amrulah \\ Fatah, David Indra Cahya
}

Universitas Sebelas Maret

shoffan.mujahid_2045@student.uns.ac.id

\section{Article History \\ received $1 / 9 / 2021$}

\begin{abstract}
The leadership of the millennial generation today refers to the concept of western leadership. In fact, Indonesia is a country that has various noble values of the nation. One of these noble values is the concept of Ki Hajar Dewantara's leadership. According to Ki Hajar Dewantara, the essence of education is an attempt to internalize cultural values into the child, so that the child becomes a complete human being, both mentally and spiritually. This stage of internalization of cultural values is very important in shaping the character of the millennial generation as future leaders of the nation. In addition, in the wayang saga, there are astha brata values that correlate with the noble values of Ki Hajar Dewantara. These two values when applied will form the ideal leader character. Unfortunately, the value of leadership begins to fade with the times. This writing method uses a literature review study with a sociological and historical approach. The purposes of writing this article are, (1) Ki Hajar Dewantara's noble leadership model, (2) actualizing the present noble leadership of Ki Hajar Dewantara, and (3) maintaining the noble leadership of Ki Hajar Dewantara through the noble values of astha brata.
\end{abstract}

Keywords: Ki Hajar Dewantara, Leadership, Astha Brata

\begin{abstract}
Abstrak
Kepemimpinan generasi milenial saat ini mengacu pada konsep kepemimpinan barat. Padahal, Indonesia merupakan negara yang memiliki beragam nilai-nilai luhur bangsa. Salah satu nilai luhur tersebut adalah konsep kepemimpinan Ki Hajar Dewantara. Menurut Ki Hajar Dewantara, hakikat pendidikan adalah sebagai usaha untuk menginternalisasikan nilai-nilai budaya ke dalam diri anak, sehingga anak menjadi manusia yang utuh baik jiwa dan rohaninya. Tahapan internalisasi tentang nilai nilai budaya ini sangat penting dalam pembentukan karakter generasi milenial sebagai calon pemimpin bangsa. Selain itu, dalam hikayat wayang terdapat nilai-nilai astha brata yang berkorelasi dengan nilai luhur dari Ki Hajar Dewantara. Kedua nilai ini apabila diterapkan akan membentuk karakter pemimpin yang ideal. Sayangnya, nilai kepemimpinan tersebut mulai luntur seiring dengan perkembangan zaman. Metode penulisan ini menggunakan kajian literature review dengan pendekatan sosiologis dan historis. Tujuan dari penulisan artikel ini yaitu, (1) model kepemimpinan luhur Ki Hajar Dewantara, (2) mengaktualisasikan kepemimpinan luhur Ki Hajar Dewantara masa kini, dan (3) menjaga kepemimpinan luhur Ki Hajar Dewantara melalui nilai luhur astha brata.
\end{abstract}

Kata kunci: Ki Hajar Dewantara, Kepemimpinan, Astha Brata

Social, Humanities, and Education Studies (SHEs): Conference Series https://jurnal.uns.ac.id/shes

p-ISSN 2620-9284

e-ISSN 2620-9292 


\section{PENDAHULUAN}

Sifat kepemimpinan merupakan aspek penting dalam kehidupan, tidak terkecuali dalam kehidupan bernegara karena sifat kepemimpinan menjadi salah satu faktor dalam pembangunan masyarakat. Saat ini banyak problematika kepemimpinan yang terjadi, seperti kurangnya integritas, tidak dapat memberikan keteladanan, dan tidak memiliki kompetensi dalam bidangnya. Selain itu, era globalisasi saat ini mudah sekali untuk mendapatkan referensi kepemimpinan dari filosofi budaya barat yang tidak sesuai dengan budaya masyarakat Indonesia.

Filosofi kepemimpinan barat apabila tidak dibarengi dengan pendalaman filosofi kepemimpinan nasional yang berlandaskan nilai luhur budaya maka akan dapat menghilangkan jejak identitas kepemimpinan nasional. Oleh karena itu diperlukan restorasi kepemimpinan nasional untuk mengembalikan pada filosofi bangsa sendiri. Salah satu filosofi kepemimpinan yang dapat menjadi referensi kepemimpinan nasional adalah filosofi kepemimpinan Ki Hajar Dewantara. Dalam kepemimpinan tersebut terdapat tiga prinsip mendasar yang harus dimiliki oleh seorang pemimpin yaitu, "Ing Ngarso Sung Tuladha, Ing Madya Mangun Karsa, Tut Wuri Handayani.

Penelitian ini menjadi penting karena membahas tentang kepemimpinan nasional. Tujuan dari penelitian ini adalah untuk menemukan proses restorasi kepemimpinan nasional, maka yang perlu untuk menjadi pembahasan adalah cara membumikan filosofi kepemimpinan Ki Hajar Dewantara

agar mudah diterima oleh masyarakat dan bisa diterapkan secara langsung. Perlu dihadirkan solusi dan metode untuk menuju restorasi kepemimpinan nasional dengan nilai luhur budaya bangsa tersebut sehingga identitas kepemimpinan bangsa Indonesia bisa terus eksis di pusaran era globalisasi.

\section{METODE}

Metode penelitian yang digunakan dalam penelitian ini yaitu literature review. Literature review merupakan cara yang dipakai untuk mengumpulkan data atau sumber yang berhubungan pada sebuah topik tertentu yang bisa didapat dari berbagai sumber seperti jurnal, buku, internet dan pustaka lain.

\section{HASIL DAN PEMBAHASAN}

Beragam Memuat hasil dan pembahasan tentang penelitian yang dilakukan, termasuk tabel, dan gambar yang disajikan. Penomoran harus diberikan pada tabel dan gambar berdasarkan urutannya.

\section{Teori Kepemimpinan ki Hajar Dewantara dalam Perspektif Sejarah}

Nama asli Ki Hajar Dewantara adalah Soewardi Soerjaningrat. Nama beliau begitu terkenal di Indonesia, khususnya di dunia pendidikan. Beliau pernah diangkat menjadi Menteri Pendidikan dan Kebudayaan pasca Indonesia merdeka. Selain itu, beliau juga merupakan pahlawan nasional karena jasa-jasanya yang begitu banyak untuk bangsa ini. Sebagai penghargaannya setiap tanggal 2 Mei diperingati Hari Pendidikan Nasional yang tertuang dalam Keppres No. 316 Tahun 1959.

Tiga prinsip dasar kepemimpinan yang digagas oleh Ki Hajar Dewantara yaitu: Ing Ngarso Sung Tuladha, Ing Madya Mangun Karsa, Tut Wuri Handayani. Ketiga prinsip tersebut lahir pada saat Ki Hajar Dewantara menggagas sekolah yang bernama National Onderwijs Institut atau yang dikenal dengan nama Taman Siswa. Taman Siswa ini berdiri pada tahun 1922, tepatnya pada tanggal 3 Juli di Yogyakarta.

Pada masa pemerintah Hindia Belanda, pendidikan hanya bisa diakses oleh kalangan tertentu. Padahal banyak rakyat pribumi yang ingin menempuh pendidikan. Disisi lain, sistem sekolah yang didirikan oleh pemerintah Hindia Belanda mengacu pada kurikulum Eropa. Hal ini berdampak pada kualitas peserta didik yang 
menekankan pada intelektual dan material saja, sehingga tidak cocok untuk rakyat pribumi yang memiliki jiwa gotong-royong dan kekeluargaan yang erat. Kekeluargaan yang erat ini dibuktikan dengan prinsip klasik orang terdahulu yakni, "mangan ora mangan sing penting kumpul" yang berarti meskipun tidak makan yang terpenting adalah dapat berkumpul dengan sanak keluarga. Selain menjadikan karakter anak menjadi individual dan materialistik, pendidikan ala pemerintah Hindia Belanda juga melahirkan karakter anak-anak menjadi kasar dan dan tidak peduli dengan lingkungan sekitar. Hal ini dirasa masih terjadi pada saat ini.

Melihat kondisi yang seperti itu menjadikan Ki Hajar Dewantara untuk mendirikan sekolah Taman Siswa yang menggunakan kurikulum berdasarkan pada nilai-nilai luhur bangsa. Maka tercetuslah prinsip "Ing Ngarso Sung Tuladha, Ing Madya Mangun Karsa, Tut Wuri Handayani". Pada awalnya prinsip ini dikenal dengan sebutan Patrap Triloka. Konsep Patrap Triloka ini diilhami oleh sistem pendidikan dan kepemimpinan progresif yang dikenalkan oleh Maria Montessori dari Italia dan Rabindranath Tagore dari India.

Di Era modern ini, konsep kepemimpinan Ki Hajar Dewantara masih menjadi landasan utama pendidikan di Indonesia. Apabila kita amati lebih mendalam, sejatinya tiga semboyan dalam dunia pendidikan tersebut merupakan sebuah konsep kepemimpinan yang luar biasa. Hal ini dapat terjadi karena pendidikan adalah inkubator awal dalam membentuk pemimpin masa depan. Tiga konsep kepemimpinan tersebut merupakan sebuah sebuah kerangka filosofis dalam membentuk karakter pemimpin di Indonesia yang mampu berkontribusi langsung dalam masyarakat. Menjadi sebuah keniscayaan bahwa pendidikan merupakan proses menularkan pengetahuan dan nilai-nilai yang baik. Salah satunya adalah nilai kepemimpinan Ki Hajar Dewantara yaitu:

Pertama, Ing ngarso sung tuladha (Didepan memberikan contoh atau teladan). Ajaran ini mengandung arti bahwa seorang pemimpin harus dapat memberikan teladan yang baik bagi pengikut maupun masyarakat sekitarnya. Konsep ini sangat sesuai bagi masyarakat Indonesia yang berorientasi keatas atau kepada pemimpin itu sendiri. Karena pada hakikatnya konsep ini dapat diwujudkan berdasarkan dua aspek. Kedua aspek tersebut adalah aspek negatif yang berisi hal yang tidak boleh dilakukan serta aspek positif. Hal yang dianjurkan atau seharusnya dilakukan. Dalam memberikan teladan pemimpin hendaknya memberikan keselarasan antara perkataan dan perbuatan "Practice what you preach". Pemimpin harus mampu untuk menguasai diri untuk tidak melakukan perbuatan yang dilarang serta mematuhi apa yang dianjurkan. Sehingga pemimpin dapat diikuti dan menjadi suri tauladan yang baik.

Kedua, Ing madyo mangun karso (Ditengah membangun semangat atau memberikan motivasi). Pemimpin sejati harus mampu berbaur dan bekerja sama dengan pengikut atau bawahannya. Keberadaan pemimpin ditengah-tengah anggota dimaksudkan untuk membangun dan membangkitkan motivasi serta semangat juang yang ada. Hal ini selaras dengan teori situasional yang dikemukakan oleh Paul Hersey dan Ken Blanchard. Dalam terciptanya sebuah kepemimpinan yang efektif bergantung pada kesiapan dari pengikut dalam menjalankan tugasnya. Apabila pengikut merasa kebingungan maka tugas seorang pemimpin untuk memberi arahan yang jelas. Lalu, ketika pengikut telah mampu melaksanakan tugasnya maka seorang pemimpin harus menciptakan dan membangun iklim yang suportif dan motivasi yang membangun.

Ketiga, Tut Wuri Handayani (Di Belakang memberi dorongan). Seorang pemimpin harus memberikan dorongan moral maupun semangat kepada pengikutnya. Dorongan moral ini diharapkan akan menumbuhkan semangat dan kepercayaan diri. Selain itu, sikap percaya antara pemimpin dan pengikutnya juga harus ditumbuhkan. Pemimpin harus percaya dan yakin pada kemampuan anggota atau pengikutnya. Hal ini bisa dicontohkan lewat pemberiaan sebuah amanah atau tanggung jawab kepada 
anggota tersebut. Perlu dipahami bahwa konsep kepemimpinan ketiga ini merupakan semboyan dari dunia Pendidikan yang memiliki makna filosofis yang sangat mendalam. Konsep ini bertujuan untuk menciptakan pribadi yang mandiri dan tidak bergantung kepada orang lain. Diharapkan nantinya akan muncul generasi baru yang akan berani memimpin dengan tetap membawa dan menanamkan karakter yang telah dibangun.

Pada prinsipnya manusia bukanlah makhluk yang hanya sekedar hidup, memiliki kekayaan atau menjalankan perannya di muka bumi. Manusia merupakan pemimpin bagi di dalam muka bumi atau dalam lingkup terkecil manusia adalah pemimpin bagi dirinya sendiri. Memimpin dirinya untuk senantiasa berjalan sesuai dengan norma yang berlaku dan bermanfaat untuk manusia lain. Dalam sebuah konsep pendidikan yang humanis menekankan pentingnya pelestarian eksistensi manusia itu sendiri. Hal ini berarti pendidikan memiliki peran untuk menciptakan manusia yang bermoral, berbudaya, berbudi pekerti luhur serta manusia yang memanusiakan orang lain. Menurut Ki Hajar Dewantara menyangkut daya cipta (kognitif), daya rasa (afektif), dan daya karsa (konatif)). Dalam konsep kepemimpinan dikenal dengan "Leaders by the head, the heart, and hand". Memiliki pemikiran yang visioner, hati yang lapang dan tindakan yang nyata.

Namun, realitanya dalam era globalisasi ini konsep kepemimpinan luhur yang sangat luar biasa dari Ki Hajar Dewantara mulai ditinggalkan. Pesatnya perkembangan teknologi turut mempengaruhi karakter masyarakat Indonesia. Kemudahan dalam memperoleh informasi menyebabkan lunturnya nilai-nilai luhur budaya bangsa dalam konsep kepemimpinan tersebut.

Masyarakat lebih memilih meniru dan mengadaptasi budaya dari luar negeri yang belum tentu sesuai dengan apa yang ada di Indonesia. Lebih lanjut banyak masyarakat yang tidak paham akan Trilogi kepemimpinan Ki Hajar Dewantara. Tiga hal tersebut hanya dianggap sebagai sebuah semboyan yang indah belaka. Dampaknya dapat dilihat bagaimana degradasi moral mulai dialami oleh generasi penerus bangsa, Keberadaan gadget semakin menjauhkan mereka dari nilai nilai yang ada.

\section{Relevansi Kepemimpinan Asta Brata}

Kepemimpinan Asta Brata merupakan contoh kepemimpinan hindu yang terdapat dalam Itihasa Ramayana, yakni delapan tipe kepemimpinan yang merupakan delapan sifat kemahakuasaan Tuhan. Penerapan kepemimpinan yang baik dalam Asta Brata haruslah selalu memiliki sifat wiweka (sikap berhati-hati) dengan segala tingkah lakunya dalam setiap keputusan yang diambil. Hal ini dikarenakan apa yang menjadi keputusannya akan diikuti oleh para rakyat yang dipimpinnya, dan sebagai seorang pemimpin maka setiap tindak perilakunya akan menjadi contoh bagi orang lain. Pemimpin yang dapat dihormati oleh rakyatnya dari pancaran wibawa yang dimilikinya juga sebagai manifesta kekuatan dewa yang ada pada dirinya. Pemimpin sebisa mungkin membangun kepercayaan rakyatnya terhadapnya sesuai dengan dharma (kebenaran) dalam setiap kepemimpinannya. Hal tersebut dapat dibangun dengan penerapan ajaran asta brata dalam diri seorang pemimpin tersebut. Penetapan keputusan yang diambil juga harus memiliki acuan dengan harapan dapat menciptakan kemakmuran dan kesejahteraan bagi rakyatnya. Adapun ajaran Asta Brata terdapat pada bagian-bagiannya (Sudarmiati, 2020) yaitu sebagai berikut: Indra Brata (Hujan), Yama Brata (Dewa Yama), Surya Brata (Matahari), Candra Brata (Bulan), Bayu Brata (Angin), Kuwera Brata (Bijaksana Bumi), Baruna Brata (Samudra), Agni Brata (Api).

Relevansi kepemimpinan Ki Hajar Dewantara dengan penerapan kepemimpinan Asta Brata yakni, Pertama, "Ing ngarso sung tulodo" (Di depan memberikan contoh atau teladan) dimana dalam penerapannya pemimpin sudah semestinya dapat bersifat Baruna Brata, hendaknya pemimpin memiliki wawasan yang luas dan sanggup 
mengatasi setiap hal dengan penuh kearifan dan mampu mengatasi berbagai macam hambatan permasalahan dalam berjalannya seperti kekacauan organisasi, permasalahan ekonomi, politik maupun lainnya, hendaknya juga dalam memiliki wawasan seorang pemimpin juga memiliki sifat Agni Brata yakni hendaknya memiliki sifat pemberani, memiliki dedikasi yang tinggi dalam mengatasi permasalahan yang terjadi, pemimpin juga diharapkan agar meniru sifat api yang selalu berkobar dalam menghadapi segala rintangan yang ada dan tidak pernah putus asa dalam menyelesaikan permasalahan yang ada. Pemimpin hendaklah memiliki sifat Indra Brata, dimana dapat memberikan keteladanan sifat yang baik seorang pemimpin untuk dapat memberikan bimbingan kepada masyarakat, bawahannya serta untuk dirinya agar selalu berusaha menciptakan kemakmuran dan kesejahteraan. harapannya dari sifat tersebut pemimpin dapat memiliki wawasan yang luas namun juga berani serta selalu bersemangat agar dapat memberikan contoh dan keteladanan dalam hal bagi orang lain dalam menghadapi segala permasalahan yang ada.

Kedua, Ing madyo mangun karso (Di tengah membangun semangat atau memberikan motivasi). seorang pemimpin semestinya dapat bersifat Bayu Brata seorang pemimpin hendaknya memberikan keteladanan sifat yang dapat memberikan bimbingan kepada masyarakat, bawahannya serta untuk dirinya dalam menciptakan kemakmuran dan kesejahteraan. Dalam hal ini juga pemimpin hendaknya mengetahui keadaan kebutuhan dan kemauan rakyat yang paling atas sampai bawah dalam. Hendaknya pemimpin bisa berada di tengah-tengah agar bisa bersikap secara objektif dan tepat. Kuwera Brata yakni pemimpin hendaknya memiliki sifat-sifat bijaksana dan berhati agar dapat melestarikan alam sehingga tercipta suatu keseimbangan antara kehidupan manusia dengan alamnya. Ketiga hal tersebut merupakan sikap yang perlu dimiliki oleh seorang pemimpin yang berlaku Ing madyo mangun karso yang selalu dapat berbaur dengan orang lain ditengah-tengah dan memberikan rasa nyaman dan berlaku objektif dalam setiap pengambilan keputusannya.

Ketiga, adalah Tut Wuri Handayani (Di Belakang memberi dorongan). Seorang pemimpin semestinya dapat bersifat Candra Brata yakni pemimpin hendaknya dapat memperlihatkan wajah yang tenang dan berseri-seri dalam kesehariannya, sehingga akan memberikan rasa aman, keyakinan dan kebesaran jiwa yang disertai dengan rasa simpati dan penuh rasa hormat kepada orang yang dipimpinnya. selanjutnya yakni Yama Brata, yaitu para pemimpin hendaknya mengikuti sifat-sifat Dewa Yama yang dapat menegakkan hukum secara benar dan adil, yang tidak pilih kasih dalam menegakkan hukum dan dapat melindungi orang-orang yang merasa butuh perlindungan dan memberikan rasa aman dan memotivasi bahwa mereka dilindungi dan haknya sangat diperjuangkan oleh seorang pemimpin. Surya Brata seorang pemimpin juga diharapkan dapat memberikan penerangan secara benar, adil dan merata kepada dalam hal ini yakni, pemimpin dapat memberikan informasi secara terbuka dan transparan kepada rakyatnya mengenai jalannya kepemimpinan, dan juga berkewajiban untuk meningkatkan taraf hidup rakyatnya. dalam segala penentuan keputusan yang bersikap objektif dan dapat dipertanggung jawabkan. penerapan sikap tersebut pemimpin diharapkan dapat memberikan dorongan motivasi agar memberikan motivasi bagi orang lain agar selalu bisa merasa aman dan terlindungi hak-hak yang dimiliki,

\section{Model Restorasi Kepemimpinan Nasional}

Restorasi kepemimpinan nasional menjadi sebuah hal penting untuk dilakukan bersama oleh seluruh elemen bangsa Indonesia. Restorasi kepemimpinan nasional yang dilakukan dalam studi ini dikembalikan ke arah nilai-nilai luhur budaya bangsa. Nilai luhur budaya bangsa Indonesia sangat banyak. Salah satu nilai luhur budaya 
bangsa yang banyak dikenal oleh masyarakat yaitu nilai dari Ki Hajar Dewantara, yang biasa disebut Patrap Triloka. Konsep Patrap Triloka ini yaitu "Ing Ngarso Sung Tuladha, Ing Madya Mangun Karsa, Tut Wuri Handayani”. Nilai luhur tersebut sangat sering untuk diucapkan oleh berbagai kalangan, utamanya dalam pembelajaran dan nilai luhur tersebut juga menjadi slogan Kementerian Pendidikan, Kebudayaan, Riset, dan Teknologi, yaitu nilai Tut Wuri Handayani makna agung dari nilai-nilai tersebut yaitu didepan memberikan contoh ditengah membangun motivasi dan dibelakang memberi dorongan. Konsep pemikiran Ki Hajar Dewantara tersebut mengajarkan sebuah model kepemimpinan yang mengacu pada karakter generasi terdidik di Indonesia. Generasi terdidik bangsa ini, utamanya para generasi muda sudah mulai terdistorsi era terkait nilai-nilai yang diterapkan dalam kehidupan sehari-hari.

Restorasi nilai luhur budaya bangsa patrap triloka sangat menarik untuk menjadi model kepemimpinan nasional saat ini. Pandangan nilai patrap triloka yang merujuk pada kebebasan, humanisme, spiritual, budi pekerti, kekeluargaan, dan kepemimpinan nasional. Model tersebut sangat tepat dan cukup holistik untuk menjadi seorang pemimpin yang bisa dekat dengan rakyat. Kedekatan dengan rakyat menjadi hal penting untuk segera diterapkan dalam konsep kepemimpinan nasional di seluruh lini kehidupan, utamanya bagi para generasi muda. Konsep tersebut akan menjadi sebuah sarana untuk mewujudkan pemimpin yang berbudi pekerti luhur, pemikiran maju berbudaya, dan raga yang bugar dalam bertindak.

Model kepemimpinan Ki Hajar Dewantara juga berkorelasi dengan ajaran luhur kepemimpinan Jawa yaitu, Asta Brata. Ajaran Asta Brata disimbolisasikan berdasarkan sifat para dewa alam, yaitu matahari, angin, bulan, api, bumi, langit, samudera, dan bintang. Konsep batara indra yang merujuk pada sifat langit menjadi sebuah studi yang relevan dengan model kepemimpinan Ki Hajar Dewantara yang selalu memberi teladan, semangat dan dorongan. Langit memiliki makna bahwa pemimpin selalu memberi nilai tambah kepada para bawahannya dan memberi keleluasaan ilmu. Konsep ini menjadi sebuah model yang dapat kita rumuskan yaitu model kepemimpinan berkarakter dengan kombinasi heart, hands, and head. Model tersebut sangat ideal dan humanis untuk mewujudkan karakter pemimpin berbudaya luhur bangsa.

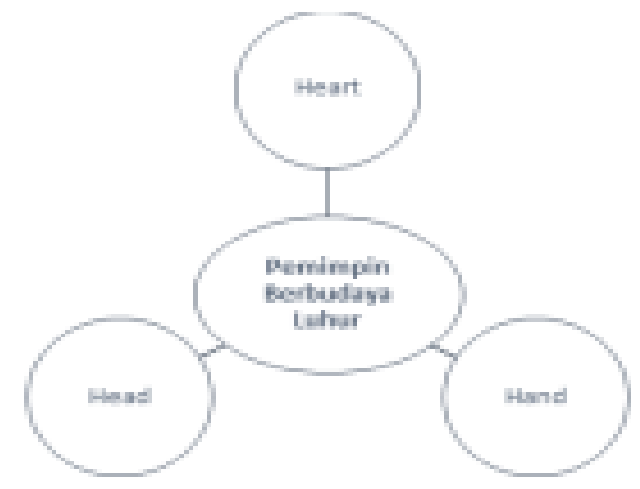

Pemimpin berbudaya luhur tersebut mengedepankan (1) hati, untuk menginspirasi dan naluri memberdayakan rakyat, (2) tangan, untuk segera mengeksekusi dan inovasi secara tanggap dan cepat, dan (3) kepala, untuk memikirkan visi ke depan sesuai prioritas. Model pemimpin luhur terintegratif tersebut telah diimplementasikan oleh $\mathrm{Ki}$ Hajar Dewantara dengan patrap triloka untuk menciptakan pemimpin dengan pendidikan berkarakter sehingga nilai luhur karakter harus terus dilestarikan. Model ini juga sangat kuat telah diajarkan dalam asta brata indra batara untuk menjadi sebuah langit yang selalu memberi teladan melalui hati yang mengerti rakyat, tangan untuk gerak cepat tanggap pada rakyat, dan kepala untuk memikirkan visi rakyat yang sejahtera di masa mendatang. 


\section{SIMPULAN}

Hasil penelitian mengenai model kepemimpinan Ki Hajar Dewantara mampu diterapkan dalam masa kini, model kepemimpinan tersebut dapat menjadi referensi dalam restorasi kepemimpinan nasional yang berlandaskan nilai luhur kebudayaan. Nilai luhur tersebut dapat tercermin dari relevansi model kepemimpinan Ki Hajar Dewantara dengan Asta Brata yang mencerminkan kebudayaan. Penelitian ini menunjukan bahwa untuk menciptakan restorasi kepemimpinan nasional maka diperlukan konsep kepemimpinan berbudaya luhur yang menyentuh sisi hati, pemikiran, dan perilaku.

Berdasarkan pembahasan dan kesimpulan dari penelitian ini maka penulis ingin memberikan saran untuk penelitian-penelitian selanjutnya. Penelitian mengenai kepemimpinan nasional harus terus dilakukan dan dikembangkan, bukan hanya diteliti oleh orang tua, akan tetapi seharusnya juga para pemuda yang akan menjadi aktor pembangunan bangsa selanjutnya. Sehingga penelitian mengenai kepemimpinan nasional dapat lebih komprehensif dari berbagai sudut pandang. Penulis juga memberikan saran kepada lembaga pendidikan untuk mulai membuat kurikulum pendidikan kepemimpinan untuk mempersiapkan pemimpin masa depan yang berbudaya luhur. Terimakasih penulis ucapkan untuk semua pihak yang telah membantu dalam pelaksanaan penelitian ini. Pertama, penulis mengucapkan terima kasih kepada Rumah Kepemimpinan yang sudah menjadi lembaga pembinaan kepemimpinan untuk penulis sehingga bisa memberikan dukungan dalam proses penulisan. Kedua, penulis mengucapkan terima kasih kepada Universitas Sebelas Maret karena telah membantu meningkatkan intelektualitas para mahasiswa dengan agenda konferensi yang bisa diikuti oleh banyak pihak. Semoga apa yang sudah dituliskan dapat memberikan kebermanfaatan secara signifikan untuk banyak orang.

\section{DAFTAR PUSTAKA}

As'ad, M., Anggoro, W., \& Virdanianty, M. (2011). Studi Eksplorasi Konstrak Kepemimpinan Model Jawa: Asta Brata, Jurnal Psikologi. https://doi.org/10.22146/jpsi.7655

Aryawan, I. W. (2021). Application of Asta Brata Leadership in Education from the Point of View of Conflict Theory, Jurnal IImiah IImu Sosial, 7(1), 56-66. https://ejournal.undiksha.ac.id/index.php/JIIS/article/view/31628

Garis, Regi Refian. (2018). "KEPEMIMPINAN PEMERINTAHAN PADA ERA GLOBALISASI (Kajian tentang Kepemimpinan Pemerintahan di Indonesia)", Moderat: Jurnal IImiah IImu Pemerintahan, Vol 4, No 1, pp. 1 - 11

Hemerling, J., Kilmann, J., \& Matthews, D. (2021). Chapter 15. The Head, Heart, and Hands of Transformation, In Mastering the Science of Organizational Change, https://doi.org/10.1515/9783110697834-015

Kumalasari, Dyah. (2010). "KONSEP PEMIKIRAN KI HADJAR DEWANTARA DALAM PENDIDIKAN TAMAN SISWA (Tinjauan Humanis-Religius)", Jurnal ISTORIA, Volume VIII, Nomor 1, pp. 47 - 59

Mallian, H. (2006). Studi Literatur tentang Model Peramalan ARMA dan Selang Kepercayaan Parameter Model dengan Menggunakan Bootstrap, Tugas Akhir, Jurusan Teknik Industri, Universitas Kristen Petra, Surabaya.

Sukri, S., Handayani, T., \& Tinus, A. (2016). ANALISIS KONSEP PEMIKIRAN KI HAJAR DEWANTARA DALAM PERSPEKTIF PENDIDIKAN KARAKTER, Jurnal Civic Hukum. https://doi.org/10.22219/jch.v1i1.10460 
Vebrianto Susilo, S. (2018). Refleksi Nilai-Nilai Pendidikan Ki Hadjar Dewantara Dalam Upaya Upaya Mengembalikan Jati Diri Pendidikan Indonesia, Jurnal Cakrawala Pendas.

Wulandari, Wida Catur. (2017). "IMPLEMENTASI TRILOGI KI HADJAR DEWANTARA DALAM KEPEMIMPINAN KEPALA SEKOLAH DI SD NEGERI 1 MERGOWATI KECAMATAN KEDU KABUPATEN TEMANGGUNG", Respotirory Universitas PFRI Yogyakarta, pp. 1 - 6

Yudiaatmaja, Fridayana. (2013). "KEPEMIMPINAN: KONSEP, TEORI DAN KARAKTERNYA", Jurnal Media Komunikasi FIS, Vol 12, No 2, pp. 29 - 38

Zainuddin, Z. (2021). Konsep Pendidikan Budi Pekerti Perspektif Ki Hadjar Dewantara, KABILAH : Journal of Social Community. https://doi.org/10.35127/kbl.v6i1.4651 